Lisbon - Malacca Port Cities Twin Conferences 2019 / 2020

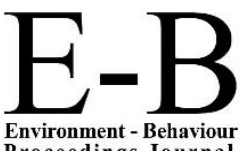

AicQoL2020Malacca

ASLI (Annual Serial Landmark International) Conferences on QoL2020

https://www.amerabra.org; https://fspu.uitm.edu.my/cebs; https://www.emasemasresources.com/

8th AMER International Conference on Quality of Life

Mahkota Hotel Melaka, Malacca, Malaysia, 18-19 Mar 2020

(Due to the Covid-19 lockdown, paper virtually presented on 25 Mar 2020)

\title{
Addressing Recent PISA Rankings: The potential role of preschool physical environment design quality in Malaysia
}

\author{
Mariam Felani Shaari 1, Sabarinah Sheikh Ahmad 1, Izaham Shah Ismail 2, Yazid Zaiki ${ }^{3}$ \\ ${ }^{1}$ Centre of Studies for Architecture, Faculty of Architecture, Planning and Surveying, \\ ${ }^{2}$ Centre of Postgraduate Studies, Faculty of Education, \\ Universiti Teknologi MARA, Malaysia \\ 3 Institute of Pharmacology, \\ National Yang-Ming University, Taiwan \\ mariamfelani@uitm.edu.my, sabar643@uitm.edu.my, izaha740@uitm.edu.my, yazidzaiki@ym.edu.tw \\ $+60125060875$
}

\begin{abstract}
Recent PISA assessments revealed unsatisfactory cognitive abilities among Malaysian children. Poor cognitive development, stemming from inadequate preschool cognitive school readiness (SR), is an underlying factor. Well-designed preschool physical environments (PPE) could potentially enhance cognitive SR and subsequently improve childhood cognitive development. This study aims to highlight the importance of PPE design quality on children's cognitive SR in Malaysia. A cohort study involving 336 children at 16 Ministry of Education (MOE) preschools was conducted. PPE design quality demonstrated a significant positive association with cognitive SR. Conclusively, better PPE design is hoped to improve cognitive development by ensuring cognitive SR among Malaysian preschoolers.
\end{abstract}

Keywords: Preschool Physical Environment; Cognitive School Readiness; Piaget's Theory of Cognitive Development; PISA

eISSN: 2398-4287 @ 2020. The Authors. Published for AMER ABRA cE-Bs by e-International Publishing House, Ltd., UK. This is an open access article under the CC BYNC-ND license (http://creativecommons.org/licenses/by-nc-nd/4.0/). Peer-review under responsibility of AMER (Association of Malaysian Environment-Behaviour Researchers), ABRA (Association of Behavioural Researchers on Asians) and cE-Bs (Centre for Environment-Behaviour Studies), Faculty of Architecture, Planning \& Surveying, Universiti Teknologi MARA, Malaysia.

DOI: https://doi.org/10.21834/e-bpj.v5i13.2057

\subsection{Introduction}

The Programme for International Student Assessment (PISA) is a widely-recognized cognitive assessment worldwide. Coordinated by the Organization for Economic Cooperation and Development (OECD), PISA evaluates proficiency in reading, mathematics, and science of 15-year-old children (OECD, 2018). Although Malaysia's ranking in PISA assessments (2012, 2015 and 2018) has improved, albeit, at an unsatisfactory rate, Malaysians remained 50 to 70 points below the global OECD average in all three aspects (MOE, 2019). In PISA, a 38-point difference is equivalent to one schooling year, implying 15-year-old Malaysians are almost two schooling years behind global averages in terms of cognitive abilities (OECD, 2018). Importantly, PISA results revealed Malaysian children lagged in problemsolving and critical thinking skills (MOE, 2019; OECD, 2018).

Since Malaysia is well-known for prioritizing education, recent PISA performances have led to mounting concern among the MOE (MOE, 2019). As a country aspiring to be fully developed, Malaysia has always envisioned an education system capable of developing

eISSN: 2398-4287 @ 2020. The Authors. Published for AMER ABRA cE-Bs by e-International Publishing House, Ltd., UK. This is an open access article under the CC BYNC-ND license (http://creativecommons.org/licenses/by-nc-nd/4.0/). Peer-review under responsibility of AMER (Association of Malaysian Environment-Behaviour Researchers), ABRA (Association of Behavioural Researchers on Asians) and cE-Bs (Centre for Environment-Behaviour Studies), Faculty of Architecture, Planning \& Surveying, Universiti Teknologi MARA, Malaysia.

DOI: https://doi.org/10.21834/e-bpj.v5i13.2057 
human capital on par with international standards. Thus, shortfalls in children's cognitive development threaten to jeopardize Malaysia's vision of citizens to spearhead the country's future growth and development (MOE, 2019).

\subsection{Literature Review}

The Malaysian Education Blueprint 2013 - 2025 (MEB 2013 - 2025) is a national transformation program to improve public education in Malaysia by 2025. One goal of MEB 2013 - 2025 was to improve Malaysia's performance in previous PISA benchmarks (MOE, 2019). To achieve this, a comprehensive roadmap to improve facilities, maximize education quality, and increase enrolment rates was outlined. The blueprint encompasses all public education institutions from preschool to post-secondary (MOE, 2019).

Concerning education for children aged four to six years old, MEB 2013 - 2025 specifies the prime objective of public preschools to maximize school readiness (SR), primarily cognitive SR, among Malaysian preschool children (MOE, 2019). Although other aspects of SR were deemed equally important, cognitive SR was emphasized. This is because cognitive SR reflects a child's level of cognitive development and is crucial as it allows them to transition seamlessly into primary school and continuously perform well in later stages of education (UNICEF, 2017). Various elements, namely higher-order thinking (HOT) skills and science, technology, engineering, and mathematics (STEM), were introduced in the preschool syllabus to enable early exposure to higher-order cognitive tasks (MOE, 2019).

Cognitive SR comprises reading, counting, color recognition, cognitive, and problem-solving skills (UNICEF, 2017). Preschool children who are cognitively ready for school are better-equipped to experience more complex cognitive tasks in primary school, allowing them to stay ahead and hone their cognitive skills. Studies show preschool cognitive SR as a crucial foundation for proper childhood cognitive development, enabling children to partake in the primary school curriculum and learning activities efficiently (Raghubar \& Barnes, 2017). Contrastingly, preschool children with low cognitive SR were found at higher risk of dropping behind peers and performing poorly in cognitive assessments later in life (Blair \& Raver, 2015). Thus, emphasis must be given to maximize cognitive SR among preschoolers to ensure correct cognitive development as they progress through childhood.

Piaget's Theory of Cognitive Development has been a mainstay in the field of children's developmental psychology and is often adopted in Western institutions to promote better school and preschool building designs to maximize cognitive development (Schultz \& Schultz, 2016). For preschool-aged children, Piaget's theory states that the preschool physical environment (PPE) is an essential source of positive stimuli to encourage correct cognitive development (Moore, 2012). Based on the theory, PPE design quality must ensure a conducive learning experience to maximize children's grasp of knowledge in classes. Furthermore, the PPE must be designed to reinforce positive learning experiences and minimize negative ones for children's cognitive development to take effect. Without appropriately designed PPE, other elements of the preschool system cannot function properly; an excellent syllabus program can't be conducted properly without a conducive classroom, and so forth.

Applying this theory in preschool design, an ideal PPE must first comfortably accommodate all preschool users. PPEs must also amplify positive stimuli by establishing appropriate indoor environment quality (IEQ), promote unobstructed teacher-children interaction, and allow exploratory behavior (Shaari \& Ahmad, 2018; Mohidin et al., 2015). Well-designed PPEs should also minimize distressing stimuli by insulating classroom users from unwanted distractions as well as visual, noise, and air pollution. All the features mentioned above enhance cognitive development and resulting cognitive SR by encouraging positive play behavior, stimulate curiosity as well as promote interest in learning among preschool children (Abbas et al., 2016).

Unfortunately, amidst constraints, PPE design quality of public preschools remains overlooked in Malaysia; quality is often compromised for quantity. However, nowadays, better PPE design does not necessarily entail significantly higher long-term costs. In truth, a better choice of site, innovative spatial design, and sustainable approaches can greatly improve the long-term cost-to-benefit ratio of public preschools. The misconception of "better quality is always expensive" is increasingly untrue (Alwetaishi \& Gadi, 2018).

Despite MEB 2013 - 2025 initiatives and improving enrolment rates, the cognitive abilities of Malaysian children remain below the OECD average (MOE, 2019). Unsurprisingly, a review of the literature revealed no previous study to look at the association between PPE design quality and cognitive SR in Malaysian public preschools. Lack of awareness of the importance of PPE design quality to encourage cognitive development and subsequent cognitive SR may be the reason for lack of attention by policymakers. Hence, this study aims to explore the possible relationship between PPE design quality and preschool children's cognitive SR in Malaysian public preschools to coax stronger awareness of the importance of PPE design quality in childhood education and encourage future studies to incorporate better PPE design elements into Malaysian public preschools.

\subsection{Methodology}

\subsection{Aim and Objectives}

The aim is to determine the relationship between PPE design quality and cognitive SR among MOE preschools in Klang Valley. The objectives are to evaluate the status of PPE design quality and cognitive SR of MOE preschools and pre-schoolers, respectively.

\subsection{Study Design}

The theoretical foundation of this study is the Piagetian approach to preschool design and childhood cognitive development. Thus, the assessment tools chosen to assess both PPE design quality and cognitive SR must be based on this approach. The Children Physical Environment Rating Scale 5 (CPERS5) is an established post-occupancy evaluation tool to assess preschool design quality against the Piagetian approach, hence, it is deemed most suitable for this study to fit the theoretical framework (Moore, 2012). Here, the examiner 
conducts an independent comprehensive survey of the preschool building and scores it according to the CPERS5 tool. It assesses four main elements of the preschool building - planning, building as a whole, children indoor spaces, and outdoor areas. Each preschool's overall PPE design quality is rated as Poor $(0.00-1.00)$, Fair $(1.00-2.00)$, Good $(2.00-3.00)$, or Excellent $(3.00-4.00)$ based on CPERS5 scores.

After CPERS5 assessments, cognitive SR of participating children is then assessed using the Bracken School Readiness Assessment (BSRA)-3 tool (Bracken, 2007). This tool is designed to assess preschool children's cognitive capabilities and reflects a child's cognitive readiness for primary school. For this tool, the examiner asks the child standard questions (based on the BSRA-3 manual) and scores the child on correct answers. Only the examiner will conduct the test to avoid bias. It assesses children's proficiency in color, letters, numbers, shapes, and sizes (elements crucial for cognitive capabilities), appropriate for preschool-aged children. BSRA3 evaluates a child's cognitive SR before and after some time and allows for the examiner to calculate whether a significant change in children's cognitive SR has occurred over some time.

To look at the association of PPE design quality of a particular MOE preschool and children's cognitive SR whilst attending the aforementioned preschool, a prospective cohort study involving $16 \mathrm{MOE}$ preschools in Klang Valley and 336 pre-schoolers was conducted. This method was chosen as it allows the study to prospectively observe particular behavioral changes among human subjects within a setting over a standardized period. MOE preschools were chosen because they cater to the broadest range of social demographic backgrounds compared to other public preschools (KEMAS, PERPADUAN, and PERMATA). Klang Valley was selected as the region with the most balanced demographic distribution in Malaysia. Only MOE preschools in Klang Valley purpose-built under the MOE Preschool Project was included. Further, only preschools with six-years-old children were selected to ensure all participating children were exposed to the same syllabus, teaching, and social environment throughout the study.

A total of 21 normal pre-schoolers were randomly selected from each preschool. This is done to standardize the number of participants per school. Cognitive SR of each pre-schooler before and after the study period at the selected MOE preschools was measured with BSRA-3. Then, the BSRA-3 final score is obtained using this formula:

BSRA-3 Final Score = BSRA-3 Post-Test - BSRA-3 Pre-Test

BSRA-3 Post-Test is the score obtained by children at the end of the study period, while BSRA-3 Pre-Test is the score obtained at the beginning of the study. The BSRA-3 Final Score reflects the change in cognitive SR of a child whilst attending a particular preschool.

To finally achieve the aims of this study, a Pearson's correlation analysis was conducted to look at the association between PPE design quality and cognitive SR. Pearson's correlation was chosen because, according to Field (2013), it's known as the best method of computing association between variables based on parametric covariance; which is the exact nature of the variables in this study.

\subsection{Variables}

The independent variable is the selected MOE preschools. The dependent variable is the level of cognitive SR among six-year-old preschoolers attending the selected MOE preschools. Constant variables are the preschool type and location, as well as the respondent's age, nationality, and additional education experience.

\subsection{Limitations}

This study is confined to preschools with the above criteria (the type of preschool, location, built year, and age of children served). Therefore, this study could not be generalized to other populations. Additionally, only one evaluator was employed in this study. Although best efforts have been made to maintain consistency of assessment, bias may be present in the evaluation process.

\subsection{Data Analysis}

Normality and reliability testing of CPERS5 and BSRA-3 raw data were conducted. Then, significance testing of BSRA-3 results using paired T-Test was done. Finally, Pearson's correlation analysis was conducted to determine the relationship between CPERS5 and BSRA-3 final scores. All statistical analyses were done using SPSS version 21.

\subsection{Findings}

\subsection{CPERS5 Results - PPE Design Quality of MOE Preschools}

Table 1. CPERS5 score and rating of MOE preschools $(N=16)$

\begin{tabular}{llll}
\hline Preschool & Cohort & CPERS5 Score & Rating \\
\hline Preschool A & Cohort 1 & 2.26 & Fair \\
Preschool B & Cohort 2 & 2.18 & Fair \\
Preschool C & Cohort 3 & 2.12 & Fair \\
Preschool D & Cohort 4 & 2.11 & Fair \\
Preschool E & Cohort 5 & 2.07 & Fair \\
Preschool F & Cohort 6 & 2.05 & Fair \\
Preschool G & Cohort 7 & 2.02 & Fair \\
Preschool H & Cohort 8 & 2.00 & Fair \\
Preschool I & Cohort 9 & 1.90 & Fair
\end{tabular}




\begin{tabular}{llll} 
Preschool J & Cohort 10 & 1.79 & Fair \\
Preschool K & Cohort 11 & 1.76 & Fair \\
Preschool L & Cohort 12 & 1.77 & Fair \\
Preschool M & Cohort 13 & 1.71 & Fair \\
Preschool N & Cohort 14 & 1.51 & Fair \\
Preschool O & Cohort 15 & 1.52 & Fair \\
Preschool P & Cohort 16 & 1.49 & Fair \\
\hline
\end{tabular}

Table 2. Normality test of CPERS5 scores ( $N=16)$

\begin{tabular}{lllll}
\hline Shapiro-Wilk (Sig.) & Z-Skewness & Z-Kurtosis & Mean & S. D. \\
\hline 0.187 & -0.668 & -1.009 & 1.89 & 0.249 \\
\hline \multicolumn{4}{c}{ (Source: Author) } \\
\hline
\end{tabular}

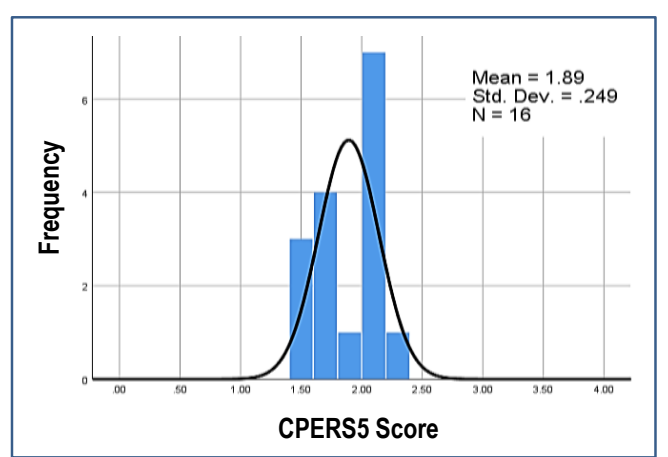

Fig 1. Histogram and normality curve of CPERS5 scores $(\mathrm{N}=16)$

(Source: Author)

Table 3. Reliability test of CPERS5 scores ( $\mathrm{N}=16)$

\begin{tabular}{|c|c|c|c|c|}
\hline CPERS5 Item & Corrected Item-Total Correlation & Cronbach's Alpha ( $\alpha$ ) if Item Deleted & No. of Items & Cronbach's Alpha (a) \\
\hline Part A : Planning & 0.273 & 0.801 & 5 & 0.813 \\
\hline Part B : Building As A Whole & 0.454 & .0785 & & \\
\hline Part C : Children's Indoor Spaces & 0.737 & 0.794 & & \\
\hline Part D : Outdoor Areas & 0.711 & 0.807 & & \\
\hline CPERS5 Score & 1.000 & 0.783 & & \\
\hline
\end{tabular}

\subsection{BSRA-3 Results - Cognitive SR of MOE Pre-schoolers}

Table 4. BSRA-3 score of MOE preschools ( $N=336)$

\begin{tabular}{llllll}
\hline BSRA-3 Score & N & Min & Max & Mean & Grade \\
\hline Pre-Test $^{*}$ & 336 & 7 & 85 & 36.51 & Moderate \\
Post-Test $^{*}$ & 336 & 14 & 85 & 46.98 & Moderate \\
BSRA-3 Final Score & 336 & -16 & 41 & 10.47 & n.a. \\
\hline
\end{tabular}

${ }^{*}$ Paired T-test $p$ value $=0.001$ (Significant difference, $p<0.05$ )

(Source: Author)

Table 5. Normality test of BSRA-3 final score $(\mathrm{N}=336)$

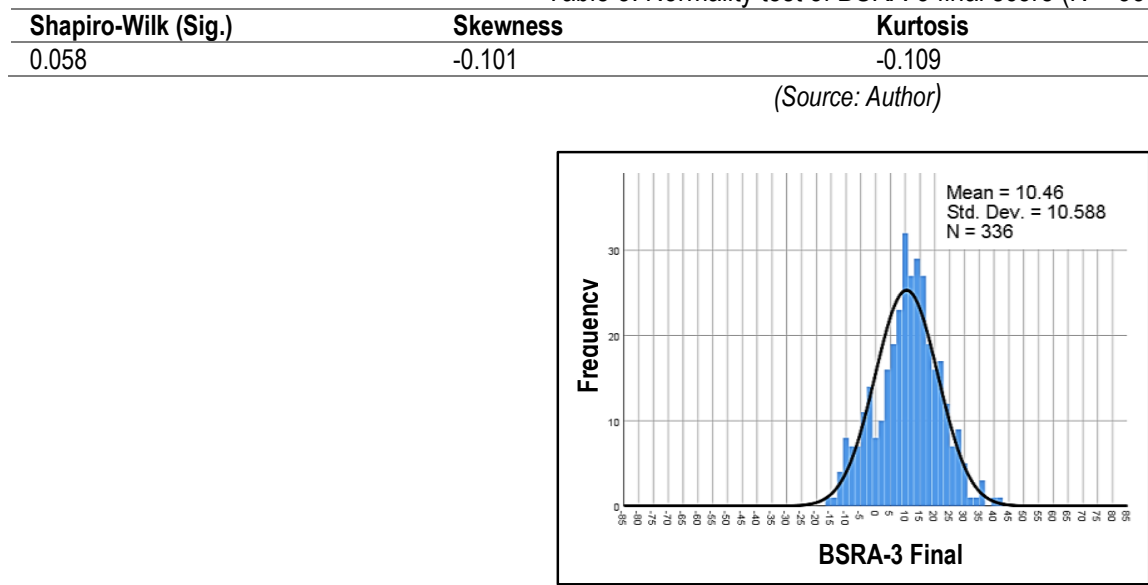

Fig 2. Histogram and normality curve of BSRA-3 final scores $(N=336)$ 
(Source: Author)

Table 6. Reliability test of BSRA-3 final scores $(\mathrm{N}=336)$

\begin{tabular}{lclll}
\hline CPERS5 Item & Corrected Item-Total Correlation & Cronbach's Alpha (a) if Item Deleted & No. of Items & Cronbach's Alpha (a) \\
\hline Subtest 1: Colors & 0.290 & 0.746 & 6 & 0.750 \\
Subtest 2: Letters & 0.528 & 0.728 & & \\
Subtest 3: Numbers & 0.589 & 0.712 & \\
Subtest 4: Sizes & 0.649 & 0.696 & \\
Subtest 5: Shapes & 0.614 & 0.682 & \\
BSRA-3 Final Score & 1.000 & 0.629 & \\
\hline & (Source: Author)
\end{tabular}

\subsection{Pearson's Correlation Analysis - Association of PPE Design Quality and Cognitive SR of MOE Preschools}

Table 7. Pearson's correlation analysis of CPERS and BSRA-3 final scores $(N=336)$

\begin{tabular}{lll}
\multirow{2}{*}{ Item } & \multicolumn{3}{c}{ BSRA-3 Final Score } \\
\cline { 2 - 3 } & r-coefficient & p-value \\
\hline CPERS5 Score & 0.57 & 0.001
\end{tabular}

(Source: Author)

\subsection{Discussion}

\subsection{Status of PPE Design Quality and Cognitive SR Among MOE Pre-schoolers in Klang Valley}

Table 1 (CPERS5 results) shows all assessed preschools were only rated Fair; no preschools were Poor, but none were Good nor Excellent. Overall, this validates the notion that public preschools are indeed lacking in terms of PPE design quality. More improvements are needed to ensure better quality across all aspects of the preschool building and a higher PPE design quality rating.

The generally low CPERS5 score was due to small building size and low-quality design of the common core of shared facilities. However, most preschools were excellent in terms of circulation design. For most assessed MOE preschools in Klang Valley, circulation is generally good because of the overall simple and square shape of their buildings, but lack space for common shared facilities (teacher office, toilets, and kitchen). This was also due to most preschools being a single story, allowing for better and less confusing circulation for preschool children. This highlights the importance of ample size in preschool design as it often jeopardizes other essential design features (Azhari et al., 2015).

Furthermore, most assessed preschools were deficient in terms of spatial design and mediocre in modified open-planning of classrooms. Quite, messy, and physical activity areas were all poor. The study found the main reason for this is that most activity areas were too exposed and not adequately isolated from each other, causing distractions during learning sessions. Some key activity areas, such as reading and painting were not covered with adjustable partitions or movable furniture. This was again attributed to inadequate space leading to the poor spatial allocation of crucial activity areas within classrooms, making it a crucial factor for low CPERS5 scores. Here we see the quality of activity spaces are the main shortfall of public MOE preschools and not at the level expected to maximize children's cognitive SR.

However, most preschools were excellent in terms of indoor environment quality. All preschools had adjustable window slits for ventilation, ample artificial lighting to ensure appropriate visual comfort, and suitably placed ventilators in kitchen and toilet areas to ensure good indoor air quality (IAQ). Nevertheless, improvements could be made by fitting adjustable lights for sleeping areas.

Also, most preschools were rated good in terms of safety and security. As expected, safety and security aspects of MOE preschools should be generally good because they are located inside primary school compounds, capitalizing on parameter and surrounding safety features. This resulted in preschool buildings being far from road traffic, visible to security personnel and often surrounded with ample fencing. This is consistent with MOE's main purpose for MOE preschool design; the site location functions as an advantage for MOE preschools and must be applied in other public preschools nationwide.

In terms of normality of CPERS5 data, Table 2 and Figure 1 showed data $(N=16)$ are normally distributed with a mean of 1.89 and a standard deviation of 0.249 . Shapiro-Wilk, Z-kurtosis, and Z-Skewness values were all within normal ranges. The reliability test of CPERS5 data shown in Table 3 demonstrates Cronbach's Alpha (a) value of 0.813 . Cronbach's Alpha (a) value for each CPERS5 part if the deleted range between 0.783 and 0.807 . Conclusively, the collected CPERS5 data portray high reliability, in agreement with Field (2013). This allows for parametric correlation analysis in a later stage of the study.

Regarding cognitive SR, Table 4 shows MOE pre-schoolers are only moderately ready for school. Worryingly, children who scored average and below on readiness tests are very likely to face learning difficulties in primary school (Bracken, 2007). To consider children to be satisfactorily ready for school, they must at least be categorized as "advanced". Interestingly, this finding supports the earlier suggestion that Malaysian children are not fully ready for primary school, especially cognitively. This may well be a contributing factor to Malaysia's declining performance in recent PISA assessments because as UNICEF (2017) argues, children who are not fully ready for school frequently transition poorly into primary school and often perform poorly in later stages. 
Paired T-test of Table 4 results further show that there have been significant improvements in BSRA-3 results $(p=0.001)$ during the study period and MOE pre-schoolers improved in all aspects of cognitive competencies. This is generally consistent with baseline expectations as children are expected to demonstrate positive cognitive development during their pre-schooling period. A more worrying result would be negative cognitive development, which is not the case in this study.

However, one may argue that in this study, most sampled preschool children entered preschool with low levels of cognitive SR, to begin with (as reflected in BSRA-3 Pre-Test results) and only had one-year preschool education. Hence, even the best MOE preschool in Malaysia might not be able to significantly increase their cognitive SR. Therefore, ultimately, the reason why the children only ended their preschool education with moderate levels of cognitive SR may not be due to PPE quality, but other factors. This is an interesting point of discussion. Though this question may well be true, there are a few noteworthy counter-arguments.

Firstly, this remains inconclusive because there were no excellent preschools in this study, to begin with, hence no evidence to substantiate this claim. Of note, the study sampled preschools with only six-year-old children, hence, as far as six-year-old children were concerned, there were indeed no MOE preschools of excellent PPE quality in Klang Valley, Malaysia - the presence of excellent preschools would enable us to argue this.

Secondly and most importantly, policymakers and stakeholders would expect a good preschool system to ensure all students achieve "advance" cognitive SR, as Bracken (2007) strongly argues. Thus, fully functional MOE preschools should be able to enhance cognitive SR more than what is seen in this study. Moreover, the MOE themselves aspire preschools to boost children's development and actively prepare children for primary school, not act as passive bystanders or mere checkpoints in the child's life (MOE, 2019). Therefore, to successfully achieve this aspiration, MOE preschools must be designed to maximize this objective, regardless of the child's background, as per any other preschool in developed countries (Dayaratne, 2016).

In terms of normality of BSRA-3 final scores, Table 5 and Figure 2 showed data $(\mathrm{N}=336)$ are normally distributed with a mean of 10.46 and a standard deviation of 10.588. Shapiro-Wilk, Z-kurtosis, and Z-Skewness values were all within normal ranges. The reliability test of BSRA-3 data shown in Table 6 demonstrates Cronbach's Alpha (a) value of 0.750. Cronbach's Alpha (a) value for each BSRA3 subscale if the deleted range between 0.629 and 0.746 . Conclusively, the BSRA-3 data portray high reliability, in agreement with Field (2013). Again, this allows for parametric correlation analysis in the later stages of the study.

\subsection{PPE Design Quality Demonstrates Significant Positive Association with Cognitive SR}

Table 7 shows overall PPE design quality demonstrates a significant positive association with children's cognitive SR $(r=0.57, p=$ 0.001) among Malaysian public MOE preschools in Klang Valley. Pearson's correlation results support the theoretical framework for this study; there is a significant relationship between PPE design quality and cognitive SR among Malaysian public MOE preschools. Piaget's Theory of Cognitive Development stipulates that children develop in response to stimuli from the physical environment. Thus, better PPE design quality results in better cognitive development and subsequent cognitive SR. Hence, Piaget's theory perfectly explains the aforementioned observation (Schultz \& Schultz, 2016).

Importantly, as Moore (2012) argued, activity areas should be able to accommodate children's pretend play and encourage explorative behavior to stimulate meaningful learning. To optimize cognitive development, children must feel attracted to study, learn and explore in their preschools. They must be invited and reinforced to receive positive stimuli from the surrounding environment. The overall size of the preschool must also be maximized (at least $4 \mathrm{~m} 2$ for each student catered) to ensure all activity areas have ample space to allow children to explore and feel comfortable in their classroom. Further, better PPE design quality could be achieved by implementing concepts of modified open-plan in the design of activity spaces. This goes back to corroborate discussions in subsection 5.1 whereby most assessed preschools were poor in terms of spatial design and mediocre in modified open-planning of classrooms. This too supports the theoretical framework proposed in this study.

However, the fact that overall center size and quality of module design in preschools only act as a crucial foundation for other aspects of the PPE to function properly is also a crucial takeaway. Other aspects namely common core of shared facilities, IEQ, quality of module design and spatial definition of activity spaces must also be good to achieve high cognitive development (Moore, 2012). But these can only be achieved through correct and holistic planning of public preschools, to begin with. Unsurprisingly, these elements were only fair in quality, potentially resulting in the only average level of cognitive SR of the pre-schoolers in this study.

\subsection{Conclusion and Recommendation}

Findings show that PPE design quality of public MOE preschools is only fair and that many improvements are needed for them to enhance cognitive development and subsequent cognitive SR among Malaysian children. Unsurprisingly, cognitive SR among Malaysian children who attend public MOE preschools were also moderate and unsatisfactory. This explains why MOE public preschool initiatives were incapable to help Malaysia to satisfactorily improve its recent PISA rankings; even after almost two decades of implementation. As practiced in developed countries, well-designed preschools are often found to result in better cognitive development and subsequent cognitive SR among children. Hence, better PPE design quality among public preschools would indeed enhance cognitive development among Malaysian children to ensure that they enter primary school fully ready. Such improvements could go a long way to ensure Malaysian children are afforded better cognitive development and perform significantly better as they progress later in life. Ultimately, Malaysian children with better cognitive abilities will surely perform better in future PISA assessments. This study hopes that more attention could be given to improve the PPE design quality of MOE preschools in Malaysia as it is associated with better cognitive SR and cognitive development among pre-schoolers. 


\section{Acknowledgments}

The authors thank Professor Gary T Moore for the use of The Children's Physical Environments Rating Scale (CPERS5). Acknowledgment is extended to the Ministry of Higher Education of Malaysia for providing the Fundamental Research Grant Scheme (FRGS), reference: 600-RMI/FRGS 5/3 (113/2015).

\section{References}

Abbas, M. Y., Othman, M., \& Rahman, P. Z. M. A. (2016). Pre-School Children's Play Behaviour Influenced by Classroom's Spatial Definitions? Asian Journal of Environment-Behaviour Studies, 1(1), 49-65.

Alwetaishi, M., \& Gadi, M. (2018). Toward sustainable school building design: A case study in hot and humid climate. Cogent Engineering, 5, 145-165.

Azhari, N. F. N., Qamaruzaman, N., Bajunid, A. F. I., \& Hassan, A. (2015). The quality of physical environment in workplace childcare centers. Procedia-Social and Behavioral Sciences, 202, 15-23.

Blair, C., \& Raver, C. C. (2015). School Readiness \& Self-Regulation: A Developmental Psychobiological Approach. Annual Review of Psychology, (66), 711-731.

Bracken, B., A. (2007). BSRA-3 Examiner's Manual.Pearson, San Antonio.

Dayaratne, R. (2016). Creating Places Through Architecture: Can Environment-Behaviour Help?. Asian Journal of Behavioural Studies, 1(2), 1-12.

Field. A. (2013). Discovering Statistics Using IMB SPSS Statistics. $4^{\text {th }}$ Edition. SAGE Publications Ltd.

Ministry of Education (MOE). (2019). Malaysia Education Blueprint 2013-2025 (Preschool to Post-Secondary Education). Retrieved from https://www.moe.gov.my/images/dasar-kpm/articlefile_file_003108.pdf

Mohidin, H. H. B., Ismail, A. S., \& Ramli, H. B. (2015). Effectiveness of Kindergarten Design in Malaysia. Procedia-Social and Behavioral Sciences, $202,47-57$.

Moore, G. T. (2012). Update on The Children's Physical Environments Rating Scale (CPERS5). Children Youth and Environments, 22(2), 311-312.

Organisation for Economic Cooperation and Development (OECD), (2018). Retrieved from http://www.oecd.org/pisa/test.

Raghubar, K. P. \& Barnes, M. (2017). Early Numeracy Skills in Preschool-Aged Children: A Review of Neurocognitive Findings and Implications for Assesement. Clin Neuropsychol., 31(2), 329-351.

Schultz, D. P., \& Schultz, S. E. (2016). A History of Modern Psychology. Cengage Learning, Nelson Education, Ltd., Boston.

Shaari, M. F., \& Ahmad, S. S. (2018). Preschool Design and School Readiness. Asian Journal of Quality of Life, 3(10), 109-120.

Shaari, M. F., \& Ahmad, S. S. (2016). Physical Learning Environment: Impact on Children School Readiness in Malaysian Preschools. Procedia-Social and Behavioral Sciences, 222, 9-18

UNICEF (2017). School Readiness A $\quad$ Conceptual $\quad$ Framework. Retrieved from https://www.unicef.org/earlychildhood/files/Child2Child_ConceptualFramework_FINAL(1).pdf. 